\title{
Power, Knowledge and Learning: Dehegomonising Colonial Knowledge
}

\section{Brenda Leibowitz}

\begin{abstract}
This article contributes to the debate on the decolonisation of knowledge by discussing the varieties of harm generated by Western enlightenment knowledge, which affects the colonised and oppressed, as well as the colonisers and privileged. The harm is discussed in relation to five points: it is interwoven with violence and imposition; it generates inequality; it leads to alienation; it lacks a foil to counter its own excesses; and it fails to answer the pressing challenges of our time. Several dehegemonising approaches are considered, including centring knowledge in relation to place; an ecology of knowledges; decolonisation from the outside; hybridisation; and comparison. These approaches all have value, although some contain challenges inherent to their conceptualisation. Most of these approaches are influenced by societal conditions of quality and inequality. The influence of broader conditions limits the potential impact of these dehegemonising approaches. The implications for the responsibilities of academics are delineated at the macro, meso and micro levels.
\end{abstract}

Keywords: cognitive justice; hegemony; teaching and learning; decolonisation; knowledge

\section{Introduction}

In the current era, the expressed desire for decolonising education is rapidly increasing. This is the case in South Africa (Le Grange 2016; Leibowitz \& Mayet 2016; Jagarnath 2015) as well as internationally (Taylor \& PaciniKetchabaw 2015; Battiste 2013). Since 2015, there has been a strong call to decolonise higher education curricula in South Africa, whereas worldwide, the 


\section{Brenda Leibowitz}

call has been in relation to both general and higher education. In this article, I hope to contribute to debates on the subject of decolonising South African higher education by drawing on both local and international literature, since this topic requires the benefits of a global conversation. Furthermore, I will make a case for the use of a wide range of writing on the subject of knowledge, language and literacy, and schooling and learning. By doing so, I show, firstly, how harmful the hegemonic Western knowledge systems have been, and secondly, how an underlying explanatory framework informing this harm, is based on the idea that the generation of knowledge and learning is profoundly situated and relational, involving power and social relations of in/equality. This relational and socio-cultural understanding of how knowledge is engaged with underscores the importance of alternative approaches to knowledge, as is discussed below. At the same time, a relational understanding points to the inherent tensions, complications and difficulties with advocating these alternative approaches. Hopefully, an exploration of these tensions can lead to a clearer charting of the way forward for the decolonisation of the curriculum.

The word 'relational' is used in this article to suggest how knowledgerelated practices and identities are shaped by several kinds of relationships: relations between individuals from different social classes and power formations; relationships between individuals and resources and the abundance or scarcity of these resources, especially highly valued knowledge-related resources such as texts, computers, newspapers or laboratory equipment, or, from an indigenous, anti-colonial perspective, the natural resources that children interact with (see Rowan 2015, in relation to Inuit Nunangat Pedagogy).

The relation includes situatedness in place and history (for example in a colonial context or in pre-modern epistemology - see Mignolo 2011). These relations affect one's agency, one's sensibilities and one's understanding of the world. They are cognitive, but also embodied and affective.

This article is not based on a report on a traditional empirical education study, nor a philosophical treatise or bibliographic survey. It is an attempt to bring together theorising about cognitive justice and decolonisation with matters of teaching and learning.

\section{Hegemonic Western Knowledge - What is the Harm?}

In this article the 'hegemony' of knowledge is seen as the domination of one 
body of knowledge or one way of seeing the world over others, allowing 'for one-sided, or historically dissymmetric "translations" between cultures' (Balibar 2016: 216). The hegemonisation of knowledge is when one knowledge system becomes dominant and ignores the value of or suppresses others. It is associated with globalisation and relations of power (Santos 2014). There are five key forms of harm, as discussed below.

The hegemonisation of knowledge has occurred partly or largely in sync with colonialism, and with power relations of the developed 'North' vs the 'undeveloped' 'South'. An expression adopted by Santos starkly conveys the violence inherent in this:

... epistemicide: the murder of knowledge. Unequal exchanges among cultures have always implied the death of the knowledge of the subordinated culture, hence the death of the social groups that possessed it. In the most extreme cases, such as that of European expansion, epistemicide was one of the conditions of genocide (Santos 2014: 93).

The hegemonisation of knowledge serves the interests of the powerful: 'Since scientific knowledge is not distributed in a socially equitable way, its interventions in the real world tend to serve the social groups having more access to such knowledge' (Santos 2014: 189). The hegemony of Western knowledge is problematic in five respects: it is embedded in relations of violence and imposition; it is embedded in relations of social inequality; it is interwoven with dynamics of alienation; it lacks a foil to counter its own excesses and show up its weaknesses; and it is inadequate on its own to solve questions that require attention. These are discussed below.

\section{Violence and Imposition}

The relations of power and how these influenced interaction between knowers during colonialism is well captured by Mignolo (2002), suggesting how colonial subjects were objects, rather than subjects, in hegemonic knowledge relationships. This is illustrated in the extract below which pertains to colonial relations in Latin America. Indians were not participants in the conversations, but rather, passive and silent colonial subjects: 


\section{Brenda Leibowitz}

Las Casas defended the Indians, but the Indians did not participate in the discussions about their rights. The emerging capitalists benefiting from the industrial revolution were eager to end slavery that supported plantation owners and slaveholders. Black Africans and American Indians were not taken into account when knowledge and social organisation were at stake. They, African and American Indians, were considered patient, living organisms to be told, not to be heard (Mignolo 2002: 63).

I would argue that this relationship of imposition and power colours relationships with Western hegemonic knowledge. The relations of inequality and domination are primarily amongst people; however a secondary level of inequality develops between the knowledge systems, in the sense that once a knowledge system, including the languages and discourses that are part of it, become hegemonic, an entire infrastructure emerges to support the powerful system. Ngũgĩ (1993: 35) suggests that this initial inequality leads to what he describes as 'subsequent distortions':

Thus English and the African languages never met as equals, under conditions of equality, independence and democracy, and this is the root of all subsequent distortions.

The example that would be most familiar to South Africans - of how a language becomes dominant, and maintains this dominance for the duration of the dominance of its users - is that of Afrikaans, where an entire infrastructure, including textbooks, dictionaries and academic journals, was set up to support it becoming a modern language appropriate for academic purposes. The inequality occurs because this infrastructure was not made available to the same degree to indigenous languages in this country. This infrastructure has of course received less support in the current post-apartheid era.

For the Comaroffs (2011), the imposition of Western knowledge in the colonies was part of a violent process. However those in the 'metropole' were saved from having to come to terms with the ravages of devastation that occurred in the colonies:

The segregation of metropole and colony not only obscured the humanitarian, modernizing, rule-governed, freedom-seeking face of 
liberal democracy from the exclusionary, violently secured forms of subjection, extraction, and devastation that were its underside. Colonies were zones of occupation in which the European civilizing mission was countered by the dictates of control and profit - and by the need to secure the contested frontiers held to stand between order and chaos (Comaroff \& Comaroff 2011: 92).

The point here is that this gave the lie to the innocence or fundamental righteousness of liberalism. Many of us who have been reared relatively unquestioningly within the dominance of Western liberalism have not seen the dark side of this epistemology. I include myself in this group.

Violence and force as a means to enforce the hegemony of a knowledge system occurred within colonialism, but it remains a means to do so in postcolonial settings as well. In his autobiography, The African Child (1953/1972), Camera Laye writes about how the teachers at his primary school would hit students for talking in their home language rather than in French the language of the colonisers. NgũgI (1993: 33) writes about similar instances when he was growing up in Kenya:

I have told of instances of children being punished if they were caught speaking their African languages. We were often caned or made to carry plaques inscribed with the words 'I am an ass'. In some cases our mouths were stuffed with pieces of paper picked from the wastepaper basket, which were then passed from one mouth to that of the latest offender.

From my PhD study (Leibowitz 2001) which explored the narratives of students acquiring their second language, i.e. English, there were numerous accounts of how a powerful, hegemonic language was imposed on young African people, but at the same time, full acquisition of the language - so that they could use it meaningfully - was denied to them. In the following extract from the study, we see a student who did not acquire sufficient proficiency in English because of the conditions of domination. Those living in townships and rural areas were not allowed to go to white areas without a pass:

The apartheid system played a most important part because the whites did not want to hear a thing, so I was forced to know English. The 


\section{Brenda Leibowitz}

police were very strict at that time. In rural areas we were not even allowed as scholars to go to town, otherwise we would be locked up in jail. My family's background as also poor which made things more difficult for me because I could not acquire my second language from them at home. They belonged to the lower class. ... I used to listen to some of the kids who were in the same class as me who spoke their second language [English] better than me. I used to ask my mother why she could not speak English and her reply was that she never had a pass to go to urban areas and those kids' mothers used to visit their people in towns and that is why it was easier for them to acquire their second language (Leibowitz 2001: 184).

This is a double-edged sword: a hegemonic knowledge system, or elements thereof, such as a language, are imposed on the oppressed; but the manner in which it is imposed positions them as passive, unequal users or as objects rather than subjects.

These examples from my $\mathrm{PhD}$ are cited here to stress the point that knowledge and the acquisition thereof is profoundly influenced, in this case by relations of inequality and imposition. They illustrate the point suggested in the cameo by Mignolo about Las Casas and the Indians that the hegemonisation of knowledge during relations of inequality colours how people, and young people in particular, come to know a particular knowledge or knowledge system. Mignolo's example reinforces the idea of the hegemonisation of knowledge rendering people of the South as 'objects' of knowledge rather than subjects (Makgoba \& Seepe 2004) and depriving them of a degree of agency in relation to knowledge (Ndebele 2016). However one must be careful of depicting oppressed people as fully lacking in agency, which leads too easily to a deficit paradigm. In another extract from the same $\mathrm{PhD}$ study, a rural student displays a degree of agency in relation to the acquisition of the dominant language:

When I was seven years old every weekend my mother used to go with me to her work in town. At my mother's work I used to play with her master's children. I was faced with a problem because I could not utter a single word [of their language]. ... As I was curious to learn the language, when I heard an unfamiliar word I would keep it to myself and when I arrived at home, I asked my mother the meaning of the 
word. By so doing I began to learn the language gradually (Leibowitz 2001: 128).

The student described her determination to acquire the language. Nevertheless the context in which this was done was one of apartheid, where Africans were so often servants to whites, thus a context of extreme structural inequality. In the next section I argue that a similar dynamic is at play in relation to socioeconomic inequalities more broadly.

\section{Social Inequality}

The impact of the imposition of hegemonic Western knowledge is not only felt by colonial subjects, but in relation to class based inequality, in the 'metropole' as well. This point has been made most strongly by reproduction theorists Pierre Bernstein (2000) in the UK, and Pierre Bourdieu (Bourdieu \& Passeron 2000), in France. In the case of Bernstein, young people might speak the dominant language, here English, but not the dominant variant thereof, and not the middle-class code or relation to knowledge. Bernstein (2000) stresses class relations and their influence on the production of learners' subjectivities:

Finally, social class relations through distributive regulation, distribute unequally, discursive, material and social resources which in turn create categories of the included and excluded, makes crucial boundaries permeable to some and impermeable to others, and specialises and positions oppositional identities (Bernstein 2000: 207).

\section{Alienation}

The imposition of Western knowledge forms also leads to alienated knowledge (Nyamnjoh 2012) as well as a sense of estrangement or foreignness for the new student to university (Jansen 2009). Alex de Waal (2016) maintains that 'African academics face a real divide between their real and scholarly selves' and become alienated from their craft as researchers.

Alienation is often discussed in relation to colonisation and coloniality, but it also features strongly in accounts of the mismatch between formal knowledge systems, as imposed via the discourses of middle-class schooling, and informal knowledge systems, both in colonial and non-colonial settings. 


\section{Brenda Leibowitz}

In the Southern African context Ndebele (2016: 18) writes about the dislocation of formal learning imposed monolithically by the school and church, from informal learning. This led to the impoverishing of the colonial knowledge disseminated via formal institutions, and the simultaneous impoverishing of local knowledge:

The specificity of township life as content for serious contemplation of ethical and moral choices were never a part of formal learning. Instead, a displacement occurred.

The impoverishment of both the formal knowledge system and of the informal knowledge system, or perhaps the loss of an opportunity to enrich both, is typical of education in South Africa in the current era. Ndebele continues to write about the real-life drama of living in the township, and the romances and fantasies he engaged in: life in Shakespearean England or the betrayals, dramas and triumphs of the movies.

We, the little ones at primary and secondary school, were transported through poems, novels, films, comic books, to worlds thousands of years away. In time, the more our imagination recreated those distant world into compelling reality, the less real our own immediate world became. As we progressively disengaged from it emotionally and imaginatively, it became less authentic, less accommodative, less attractive, unfulfilling and often hostile, as we lived in it. We lived in it without the concomitant learned habit of thinking it. Our affective imaginations progressively got anchored elsewhere. ...

So, all that was affectively close to me, which could shape my ethical and moral attitudes towards pain and pleasure, life and death, desire and revulsion, was never a part of learning in the world of official schooling. Nothing in my schools ever taught me about life in the township in any sustained manner. There were few opportunities to contemplate human behaviour such as would enhance the sense of human value and deepen subjectivity through informed rational discourse. It dawned on me that contemplated encounters with my immediate environment in its own settings had no institutional affirmations (Ndebele 2016: 18). 


\section{Lacking a Foil to Counter its Own Excess}

Thus far my argument has been in support of the criticism of the hegemony of Western knowledge systems in that it serves the interests of the powerful at the expense of the oppressed. However there are aspects of this hegemony which can be shown to affect the oppressed as well as the privileged. Mignolo (2002: 71-72) maintains that decolonising knowledge is 'at least as important for the coloniser as it is for the colonised'. One of these aspects is that a hegemonic knowledge system lacks a dialectical or dialogic relationship with non-Western knowledges, which present the counter to, or the limits or logical implications, of Western modernity. Santos (2014) gives an example of knowledge systems where the consequences of uncountered excesses are great - including those of eugenics and racial anthropology. Eugenics is a good example of the difficulty of dislodging western epistemology, and of the mental grooves that are created by epistemology at a deep level. Eugenics was a logical outcome of the classification and categorisation inherent in the scientific work of the enlightenment, aligned with a hierarchical or dualist mode of thinking. In the humanist era 'man' was at the centre of the university, omnipotent and omniscient. If one can see humans at the centre, as most powerful, agentic and qualitatively superior, it is a small step to seeing certain kinds of human, for example Aryans or whites, as the most superior. Eugenics is a form of epistemicide, i.e. the imposition of a knowledge system that leads to destruction of peoples or their practices. The problem with this and other aberrations is the self-confidence and the complacency of those who perpetuated these errant ways of thinking. Santos (2014) maintains that this 'blindness' is recurrent. One could argue that these blindnesses or intellectual cul de sacs can occur in any society. It just happens that this blindness has ramifications for an entire world system, not just one small group in one area.

\section{Inadequate to Answer Problems}

A second problematic aspect of a hegemonic knowledge system that affects the entire system and all members of society is that it is not aware of the gaps or silences in the system, and cannot solve its own problems:

The need for translation resides in the fact that the problems that Western modernity purported to solve (liberty, equality, fraternity) remain unsolved and cannot be resolved within the cultural and 
political confines of Western modernity. In other words, in the transition period in which we find ourselves, we are faced with modern problems for which we have no modern solutions (Santos 2014: 233).

The lack of solutions to modern problems is most poignantly felt in the current era in relation to threats against the planet and global warming, in addition to other modern as well as age-old problems. This is also a problem where many first nations and indigenous peoples claim to have more appropriate epistemologies, or knowledge systems that can contribute towards an understanding of how to live in harmony with the environment (Battiste 2013; Smith 1999).

\section{Non-hegemonising Approaches Towards Knowledge}

Thus far we have traced the harm caused by a hegemonic Western knowledge system, with examples. In this next section an array of suggestions are considered, about how to view knowledge differently, such that individuals or groups are not subject to one, overarching and impositional knowledge system.

\section{Centring Knowledge in Relation to Place}

One of the most significant approaches, or certainly the most popular in South Africa within the call to decolonise the curriculum, is to centre the knowledge in the curriculum by focusing that which is most familiar or relevant to people, and in the case of Africans, African knowledge. As a writer and teacher of literature, Ngũgĩ (1985/2005) focuses his attention on literature and language. He maintains that the priority should be Africa, and should radiate outwards other colonised nations, for example the West Indies, before moving to Western powerful knowledge. Thus place and history (colonisation) are linked. He calls this centring a 'quest for relevance' (Ngũgĩ 2005: 87), where the purpose is to be able to see oneself and others in the universe from one's own perspective. It should be stressed that this is by no means an exclusionary perspective, as it is not about rejecting Western knowledge (Mbembe n.d.). This position is convincing and credible. However it does contain inherent challenges in heterogeneous societies where, even within a continent, be it Europe or Africa, migration due to violence, conflict and economic difference has led to many children or adults of different national and linguistic 
backgrounds living or attending school together. Differences are not only national: they might be religious, gender or class based, and so on. I experienced this challenge first-hand when I was a high school English teacher in working-class coloured schools in the Western Cape in the late 1980s. Attempts to insert examples of African literature into literature curriculum were met with varying success, with stories with high affective value or those that dealt specifically with matters of interest in that coloured community, or to teenagers being more palatable - the fact that they were produced by African writers was not appreciated, even though we were (on the tip of) the African continent.

\section{An Ecology of Knowledges}

A second approach to dehegemonising knowledge is to see various knowledge systems as existing side by side, within an ecology of knowledges rather than within a hierarchy of value. The concept of 'cognitive justice' is a 'normative principle for the equal treatment of all forms of knowledge' (Van der Velden 2006: 12). This does not mean that all forms of knowledge are equal, but rather, that the equality of knowers forms the basis of dialogue between knowledges, and that what is required for democracy is a dialogue amongst knowers and their knowledges. According to this view there are a variety of knowledges which can be considered. Their relevance depends on the question being asked, as well as the process adopted to reach the answer, including social and ethical considerations,

Since no knowledge or practice in isolation provides reliable guidance, and for an edifying, socially responsible, rather than technical, application of science, fully aware that the consequences of scientific actions tend to be less scientific than the actions themselves (Santos 2014: 127).

Mbembe (2016: 37) also calls for 'epistemic diversity', which is: 'a process that does not necessarily abandon the notion of universal knowledge for humanity, but which embraces it via a horizontal strategy of openness to dialogue among many epistemic traditions'. He refers to Enrique Dussel and Boaventura de Sousa Santos on the 'pluriversity': 


\section{Brenda Leibowitz}

To decolonise the university is therefore to reform it with the aim of creating a less provincial and more open critical cosmopolitan pluriversalism - a task that involves the radical refounding of our ways of thinking and a transcendence of our disciplinary divisions (Mbembe 2016: 37).

The view that there are multiple and diverse knowledges does not necessarily imply relativism, or that 'anything goes'. For example, Visvanathan proposes a list of requirements for knowledge systems to exist side by side, and to ensure cognitive justice:

1. Each knowledge system if it is to be democratic must realise it is iatrogenic in some context.

2. Each knowledge system must realise that in moments of dominance it may destroy life-giving alternatives available in the other. Each paradigm must sustain the otherness of other knowledge systems.

3. No knowledge system may 'museumify' the other. No knowledge system should be overtly deskilling.

4. Each knowledge system must practice cognitive indifference to itself in some consciously chosen domains.

5. All major technical projects legitimised through dominant knowledge forms must be subject to referendum and recall (Visvanathan 2007: 215).

This ecological approach would rely on an institution, such as a university, to truly reconsider what its aims are, and to what ends it is educating students. For example, what kind of doctors does a medical school wish to produce? One that can conduct research at an international level? One that knows how to perform operations within a 'first world' system? Or one that is enabled, with sensitivity about a community's values and aspirations, to mount a preventative strategy against illnesses that afflict the majority of a country's inhabitants? Featuring indigenous knowledges side by side in higher education with the dominant Western enlightenment knowledge has been receiving attention, for example the launch of the Indigenous Strategy 2017-2020 in Australia, which includes the 'processes that ensure all students will encounter and engage with Aboriginal and Torres Strait Islander cultural content as integral parts of their course of study, by 2020' (Universities Australia n.d.). 
According to Page (2017), this strategy, which built on earlier work by the Deans of Medicine, has been met thus far with 'varying success'. If one is including varying cosmologies, rather than piecemeal and atomised chunks of information, students would be required to become, by analogy with the word 'multi-lingual' then 'multi-epistemic' - having access to multiple epistemologies. In this case students would need to become proficient in a range of knowledges, and have an appreciation of their purposes and relevance. This would not be impossible, but it is challenging.

The difference between the current situation, where the privileged only have to acquire the dominant Western knowledge, is that the privileged students would also require to be re-educated, since they are not currently multilingual and multi-epistemic. An interesting example of this is a collaborative project I was engaged in called Community, Self and Identity (Leibowitz et al. 2012), which required fourth year students from two universities to study a short module together, in which they learnt about matters of identity, difference and community across boundaries of institution, social class, race, gender, language and discipline. We deliberately unseated the regular norms by starting the first session using participatory learning and action techniques, with students drawing maps of their communities and their needs, rather than with them writing expository prose or talking in a discursive manner (the latter being examples of the dominant academic mode). The students who were most discomforted by the information that was elicited were the middle-class, white students. Unfortunately by the end of the module the dominant modes (presentation via powerpoint and reflective essays) in which the middle-class students were more proficient, became salient. In other words, the designers of the module were correct in our intuition that disrupting power relations by changing the mode of communication and representation could differently valorise the knowledge of the working-class, black students. But we still had to contend with the tenacity of the current modes of communication and values regarding what is valuable knowledge, sustained by assessment policies, programme outcomes and professional standards which govern the curriculum.

\section{Decolonising Knowledge from the Outside}

A somewhat different approach is that we have to decolonise knowledge by thinking outside of the Western epistemology as it is not possible to think 'from 


\section{Brenda Leibowitz}

the cannon of Western philosophy, even when part of the canon is critical of modernity. To do so means to reproduce the blind epistemic ethnocentrism that makes difficult, if not impossible, any political philosophy of inclusion' (Mignolo 2002: 66).

To decolonise knowledge in fields such as philosophy or the social sciences, requires appropriating Western epistemology and simultaneously to think within other cosmologies which are not dependent on Western modernity, and in so doing, to criticise Western modernity. This is the task involved in decolonising knowledge, but it is less clear what the implications of this are for education. Perhaps in education too, a decolonising education requires students to appropriate Western knowledge, and at the same time, to critique it from without. The latter requires being familiar with non-western knowledges. However Mignolo's position suggests a slightly different education for students in colonial settings than for those in the global North, since in the global North one may learn to rationally understand epistemologies of the South, but not to feel them in the embodied manner that those in colonial contexts would do:

Nothing prevents a white body in Western Europe from sensing how coloniality works in non-European bodies. That understanding would be rational and intellectual, not experiential. Therefore, for a white European body to think decolonially means to give; to give in a parallel way than a body of color formed in colonial histories has to give if that body wants to inhabit postmodern and poststructuralist theories (Mignolo 2011: iii).

By a 'different education' I do not mean a different school or university system, but a concept of education that assumes that there are different cosmologies, different sensibilities, rationalities and entitlements in one teaching and learning setting. Furthermore, this difference is not a comfortable or cosy one. When decolonising knowledge the embodied knowledge and sensibility of the colonised is privileged. Rather than a global village, the world is:

a series of non-homogenous pockets of identity that must eventually come into conflict because they represent different historical arrangements of emotional energy (Mignolo 2002: 69). 
Unless one is suggesting that students should be kept separate in their own spatial and historical contexts - which is both unfeasible as well as highly simplistic - then learning will of necessity involve an element of conflict about what a place-based sensibility might mean. This degree of conflict was illustrated in the Community, Self and Identity project referred to earlier, where students from different social as well as geographic locations (in the form of countries, provinces in South Africa and townships and suburbs within the Western Cape) came together to learn. The degree of conflict, which one student described as 'cognitive dissonance', led to a productive but uncomfortable learning experience (Leibowitz et al. 2012).

This approach would also require a strong degree of 'multiepistemicism' amongst students, both bearers of hegemonic knowledge forms as well as non-hegemonic forms, as well as from educators. It would be extremely challenging, but perhaps more honest, than assuming it is easy for an individual to move from one knowledge system to another, or that it is easy to integrate differing worldviews or pockets of knowledge based on different worldviews (Battiste 2013) without distorting them.

\section{Hybridisation}

Another non-hegemonic approach is the encouragement of the hybridisation of knowledges, and the medium through which knowledge is communicated, i.e. languages. Ndebele offers a solution which he has consistently maintained: not to 'compare' or 'counterpose' but rather, to creolise. A position that he expressed in 1986 concerned the hegemony of English, which he felt could be appropriated by Africans, in which case it would be an African English:

English will have to be taught in such a way that the learners are made to recognize themselves through the learning context employed, not as second class learners of a foreign culture, or as units of labour that have to be tuned to work better, but as self-respecting citizens of the world. The idea of teaching English through the exposure of second language learners to English culture should be abandoned. If English belongs to all, then it will naturally assume the cultural colour of its respective users (Ndebele 1986: 22). 


\section{Brenda Leibowitz}

Van der Waal (2012) draws on the work of Caribbean writer Edouard Glissant to consider whether the notion of creolisation and the politics of relation, do not offer a preferable solution to the essentialising of languages and language groups, including to the cultural hegemony of Afrikaans and whiteness on some of our campuses. At our SOTL @ UJ seminar where he presented this idea, the question was asked, 'could the creolised language or culture not then become a new, essentialised and hegemonic culture?' Given that Afrikaans, or English, for that matter, are creolised languages themselves, this could surely be the case. This would imply that we should not only consider creolisation or hybridity to be a solution, but in addition, the means by which this creolisation is maintained or negotiated, in new contexts of inequality. The principle of creolisation and relation do suggest an exciting way forward: for example, a student at her Rhodes graduation appeared barefoot and did a traditional IsiXhosa dance (Frederique 2016). This is an example of creolising or hybriddising our academic rituals and perhaps we should be looking far more systematically into the possibilities of this, not only regarding ceremonial rituals, but academic processes such as learning and teaching, and assessment.

Hybridisation conflicts with the argument that differing epistemologies, related to entire cosmologies, are not easily commensurate. This could be a valuable area for further research, i.e. issues of commensurability, and crossing cosmologies, ontologies, epistemologies and languages under what conditions does this become feasible, and what are the pedagogic challenges? In my own experience of conducting research on language, I am aware of instances where mixing languages (known as code-switching) has been both productive as well as problematic.

\section{Comparison}

Despite the challenges posed by having to navigate knowledge systems, there are considerable advantages. Living and learning with different knowledges forces us to reconsider the blindnesses brought about by a complacent approach to knowledge:

When two or more opposing accounts, perspectives, or belief systems appear side by side or intertwined, a kind of double or multiple 'seeing' results, forcing you into continuous dialectical encounters with these 
different stories, situations, and people. Trying to understand these convergences compels you to critique your own perspective and assumptions. It leads to reinterpreting the story you imagined yourself living, bring it to a dramatic end and initiating one of turmoil, being swallowed by your fears, and passing through a threshold (Anzaldua 2015: 125).

At a more metacognitive level, engaging in comparisons can reduce epistemic racism, for example by showing how non-Western knowledge sources have contributed to what we know as Western epistemology, especially with examples from Mathematics with its rich inputs from the Arabic world. Engaging in comparisons between knowledge systems can lead to valuable insights, provided that one does not compare, from the vantage point of the superiority of Western knowledge. The work of the Comaroff and Comaroff (2014) has been instructive, in showing systematic manifestations of similar deep social structures or processes in the South. Their most interesting example is the notion, basic to Western modernity, of the 'autonomous self'. They provide a detailed description of Tswana philosophy of the self, which in many respects is performative and individualistic, much as in the Western notion of the self. Whilst this approach has been very enlightening, and it may change views about how Western epistemology came to be and who contributed to it, it would not greatly reduce the controlling influence of present hegemonic practices.

Thus students would benefit from a more multifaceted exposure to various knowledges in the world. However the value of comparisons and exposure to diverse knowledges depends on social and material conditions of equality and inequality that influence how learners see themselves - as subject or objects.

\section{Conclusion}

As an attempt to contribute towards debate on decolonising the curriculum, this article began by sharing some of the key ways in which a hegemonic Western knowledge system generates and perpetuates harm. The discussion purposefully moved across historical eras and regions, in order to make the point that although this is very clearly an issue in South African education, it 


\section{Brenda Leibowitz}

is by no means particular to this country, and furthermore, while it is particularly harmful in the global South, it is not limited to the South. The varieties of harm that affect the oppressed are interwoven with violence and imposition; they lead to alienation; and perpetuate social inequality. The varieties of harm that affect the oppressed as well as the privileged, include the idea that the dominant hegemonic knowledge lacks a foil to counter its own excesses, and that it lacks the answers to counter the world's problems. Various approaches towards dehegemonising knowledge were surveyed, in order to argue that such a move is indeed possible. More than this, these approaches provide great intellectual advantages. However there are clear challenges in this regard, due partly to the assumptions inherent in these approaches, and party due to the relationality of knowledge production and acquisition. How students learn is strongly influenced by broader matters of power, authority and the distribution of resources. Mignolo (2011: ii) makes this point simply: 'decoloniality focuses on changing the terms of the conversation and not only its content.'

The implication of the social and relational nature of knowledge production and acquisition is that as academics we have a responsibility at three levels: at the most macro, societal level; at the meso level of academia, in our universities, professional associations and knowledge disciplinary associations; and finally, at the micro level, in our own teaching and learning contexts, when designing programmes and modules. All of the instantiations of harm targeting most directly the marginalised and oppressed, namely the relationship with violence and impositions, the maintenance and perpetuation of inequality and alienation, influence the subjectivity of the knower to the extent that there is a limit to how much change education can produce, when these structural and cultural conditions do not change. Thus if we care about the social relationships that influence learning and engagement with knowledge, we should care deeply about the social relations that impinge on learning.

The meso level of academia and its ability to change relations of power and knowledge should not be underestimated. An obvious example would be the manner in which pharmaceutical companies influence medical research and the production of medicines, at the expense of the interests of the poor. But academics do represent the interests of students and of knowledge generated in the interests of the broader community, in professional associations in particular, and can have an influence on the hierarchy of value of knowledges. 
In the example referred to earlier of the move to incorporate indigenous knowledge in universities in Australia (Universities Australia n.d.) it was the actions of medical Deans that informed this development.

At the micro level, academics have the most leeway to influence the choice of content and approach to teaching and learning, perhaps in converse relationship to the ultimate impact of our choices. This observation is in no way intended to belittle the important work of transformation at the level of teaching and learning, and interaction with students. It is meant to explain why it is so difficult to effect extensive and lasting change at the micro level, not to argue that one should not be engaging in this fundamentally important activity.

\section{References}

Anzaldua, G. 2015. Light in the Dark/ Luz en lo Oscuro: Rewriting Identity, Spirituality, Reality. Keating, A. (ed.). Durham: Duke University Press. Bernstein, B. 2000. Pedagogy, Symbolic Control and Identity: Theory, Research, Critique. Revised Edition. Lanham: Rowman and Littlefield. Balibar, E. 2016. Further Reflections on Exile: War and Translation. In Braidotti, R. \& P. Gilroy (eds.): Conflicting Humanities. London: Bloomsbury.

Battiste, M. 2013. Decolonizing Education: Nourishing the Learning Spirit. Saskatoon: Purich.

Bourdieu, P. \& J. Passeron 2000. Reproduction in Education, Society and Culture. Second Edition. London: Sage.

Comaroff, J. \& J. Comaroff. 2014. Theory from the South: How Euro-America is Evolving toward Africa. Stellenbosch: Sun Press.

De Waal, A. 2016. African Academics Face a Huge Divide Between their Real and Scholarly Selves. The Conversation 10 March 2016. Available at: http://theconversation.com/african-academics-face-a-huge-dividebetween-their-real-and-scholarly-selves-55899. (Accessed on 10 March 2016).

Frederique, D. 2016. Xhosa Dance Shakes Rhodes Graduation Ceremony. City Press 10 April 2016.

Jagarnath, V. 2015. Curriculum Conversation 6. Available at: https://www.ru. ac.za/teachingandlearning/teachingandlearningnews/curricullumconver sation6-1.html. (Accessed on 3 August 2016.) 
Jansen, J. 2009. Knowledge in the Blood: Confronting Race and the Apartheid Past. Lansdowne: UCT Press.

Laye, C. 1953/1972. The African Child. London: Collins, Fontana.

Le Grange, L. 2016. Decolonizing the University Curriculum. South African Journal of Higher Education 30,2:1-12.

Leibowitz, B. 2001. A Case Study of Students' Literacy Backgrounds and their Academic Literacy in a Multilingual South African University. Unpublished PhD Study, University of Sheffield.

Leibowitz, B. \& R. Mayet. 2016. Decolonising the Curriculum: Workshop at the University of Johannesburg. Available at: http://sotlforsocialjustice. blogspot.co.za/2016/05/decolonizing-curriculum-workshop-at.html.

(Accessed on 2 August 2016.)

Leibowitz, B., L. Swartz, V. Bozalek, R. Carolissen, L. Nichols, \& P. Rohleder (eds.) 2012. Community, Self and Identity: Educating South African University Students for Citizenship. HSRC Press.

Makgoba, W. \& S. Seepe. 2004. Knowledge and Identity: An African Vision of Higher Education Transformation. In Seepe, S. (ed.): Towards an African Identity of Higher Education. Pretoria: Vista University and Skotaville.

Mbembe, A. 2016. Decolonizing the University: New Directions. Arts and Humanities in Higher Education 15,1:29-45.

Mbembe, A. n.d. Decolonizing Knowledge and the Question of the Archive. Available at: https://africaisacountry.atavist.com/decolonizing-know ledge-and-the-question-of-the-archive. (Accessed on 2 September 2106.) Mignolo, W. 2002. The Geopolitics of Knowledge and the Colonial Difference. The South Atlantic Quarterly 101,1:57-96.

Mignolo, W. 2011. Geopolitics of Sensing and Knowing: On (De)coloniality, Border Thinking and Epistemic Disobedience. Postcolonial Studies 14,3:273-283.

Ndebele, N. 1986. The English Language and Social Change in South Africa. Keynote Address Delivered at Jubilee Conference of the English Academy of South Africa. Reproduced in: Ndebele, N. 1991. Rediscovery of the Ordinary: Essays on South African Literature and Culture. Johannesburg: COSAW.

Ndebele, N. 2016. To Be or Not to Be? No Longer at Ease. Arts and Humanities in Higher Education 15,1:15-28.

Ngũgĩ wa Thiong'o. 1993. Moving the Centre: The Struggle for Cultural Free- 
doms. Rochester: James Curry/Heinemann.

Nyamnjoh, F. 2012. Potted Plants in Greenhouses: A Critical Reflection on the

Resilience of Colonial Education in Africa. Journal of African and Asian Studies 47,2:129-154.

Page, S. 2017. The Transformative Potential of Southern SoTL for Australian Indigenous Studies. SOTL in the South 1,1:108-111. Available at: http:// sotl-south-journal.net/?journal=sotls\&page=article\&op=view\&path\%5B $\% 5 \mathrm{D}=16$. (Accessed on 1 October 2017.).

Rowan, M. 2015. Thinking with Land, Water, Ice, and Snow. In PaciniKetchabaw, V. \& A. Taylor (eds): Unsettling the Colonial Places and Spaces of Early Childhood Education. London: Routledge.

Santos, B. 2014. Epistemologies of the South: Justice against Epistemicide. Boulder, Colorado: Paradigm Publishers.

Smith, L.T. 1999. Decolonising Methodologies: Research and Indigenous Peoples. London: Zed Books.

Taylor, A. \& V. Pacini-Ketchabaw. 2015. Introduction: Unsettling the Colonial

Places and Spaces of Early Childhood Education in Settler Colonial

Societies. In Pacini-Ketchabaw, V. \& A. Taylor (eds): Unsettling the Colonial Places and Spaces of Early Childhood Education. London: Routledge.

Universities Australia n.d. Indigenous Strategy 2017-2020. Available at: http://www.universitiesaustralia.edu.au. (Accessed on 1 July 2017).

Van der Velden, M. 2006. A Case for Cognitive Justice. Available at: www.globalagenda.org/file/6. (Accessed on 1 April 2017).

Van der Waal, C.S. 2012. Creolisation and Purity: Afrikaans Language Politics in Post-Apartheid Times. African Studies 71: 446 - 463.

Visvanathan, S. 2007. Between Cosmology and System: The Heuristics of a Dissenting Imagination. In Santos, B. (ed.): Another Knowledge is Possible: Beyond Northern Epistemologies. London: Verso.

Brenda Leibowitz Faculty of Education University of Johannesburg Brendal@uj.ac.za 